\title{
Adult Erythroleukemia
}

National Cancer Institute

\section{Source}

National Cancer Institute. Adult Erythroleukemia. NCI Thesaurus. Code C68694.

An erythroleukemia occurring in adults. 